Research Paper

\title{
TGF- $\beta$ Induces Degradation of PTHrP Through Ubiquitin-Proteasome System in Hepatocellular Carcinoma
}

Hao $\mathrm{Li}^{1 *}$, Guangchun $\mathrm{He}^{1 *}$, Hui Yao ${ }^{1^{*}}$, Liujiang Song ${ }^{1}$, Liang Zeng ${ }^{2}$, Xiaoning Peng${ }^{1}$, Thomas J. Rosol ${ }^{3}$, Xiyun Deng $1{ }^{凶}$

1. Medical College, Hunan Normal University, Changsha, Hunan 410013, China;

2. Department of Pathology, The Affiliated Hunan Provincial Cancer Hospital, Xiangya School of Medicine, Central South University, Changsha, Hunan 410013, China.

3. Department of Veterinary Biosciences, The Ohio State University, Columbus, Ohio 43210, United States of America.

* These authors contributed equally to this work.

$\triangle$ Corresponding author: Xiyun Deng, E-mail: dengxiyunmed@hunnu.edu.cn; Tel: +86-731-8891-2426.

(c) 2015 Ivyspring International Publisher. Reproduction is permitted for personal, noncommercial use, provided that the article is in whole, unmodified, and properly cited. See http://ivyspring.com/terms for terms and conditions.

Received: 2014.10.16; Accepted: 2014.11.20; Published: 2015.04.05

\begin{abstract}
Both transforming growth factor- $\beta$ (TGF- $\beta$ ) and parathyroid hormone-related protein (PTHrP) regulate important cellular processes, such as apoptosis in the development of hepatocellular carcinoma. However, the mechanisms of regulation of PTHrP by TGF- $\beta$ are largely unknown. We hypothesized that TGF- $\beta$ regulates the expression of PTHrP protein through a post-translational mechanism. Using hepatocellular carcinoma cell lines as the in vitro model, we investigated the effects of TGF- $\beta$ on protein expression and post-translational processing of PTHrP. We found that TGF- $\beta$ treatment led to protein degradation of PTHrP through the ubiquitin-proteasome-dependent pathway. We also provided evidence to show that Smurf2 was the E3 ligase responsible for the ubiquitination of PTHrP. Furthermore, using immunohistochemistry on human hepatocellular carcinoma specimens and a tissue array, we found that the expression of PTHrP was predominantly in the cancer cells, whereas the expression of TGF- $\beta$ was present in non-neoplastic liver tissue adjacent to hepatocellular carcinoma. Our findings reveal a novel mechanism whereby TGF- $\beta$ may regulate PTHrP in hepatocellular carcinogenesis and lack of TGF- $\beta$ in hepatocellular carcinoma may promote cancer progression. Promotion of PTHrP degradation provides a novel target of therapeutic intervention to sensitize hepatocellular carcinoma cells to cytostatic and/or pro-apoptotic signals.
\end{abstract}

Key words: Transforming growth factor $\beta$; Parathyroid hormone-related protein; Hepatocellular carcinoma; Ubiquitination; Proteasomal degradation.

\section{Introduction}

Hepatocellular carcinoma (HCC) is the fifth and seventh most common cancer in men and women, respectively, and the third most common cause of cancer-related mortality worldwide ${ }^{1}$. According to WHO projections, the global burden of HCC, especially in industrialized countries, such as the Unites
States, United Kingdom, and Australia, is expected to rise, and by 2030 it is predicted to account for the second highest increase in cancer-related death rates ${ }^{2}$. HCCs constitute a therapeutic challenge with mostly unfavorable outcome among all the solid malignancies. For those with advanced non-resectable diseases, 
non-surgical treatments have been offered, but with little survival benefit. This may reflect our incomplete understanding of disease pathogenesis, e.g. the elucidation of tumorigenic signaling pathways. Therefore, identification of new therapeutic targets for HCC patients is imperative ${ }^{3}$.

Transforming growth factor $\beta$ (TGF- $\beta$ ) family members are multifunctional cytokines that control proliferation, differentiation, apoptosis, embryonic development, angiogenesis, wound healing, and many other functions in both normal and transformed cells ${ }^{4}$. In many types of cancers including HCC, TGF- $\beta$ functions paradoxically at different stages of tumorigenesis. During the onset of tumor formation, TGF- $\beta$ functions as a tumor suppressor via its cytostatic effects, e.g. inhibition of cell proliferation and induction of apoptosis; whereas at advanced stages of cancer, it functions as a tumor promoter aiding in tumor progression through promotion of epithelial-to-mesenchymal transition (EMT) and metastasis. Alternatively, the tumor-suppressive role of TGF- $\beta$ is lost at the later stage of carcinogenesis due to disruption of TGF- $\beta$ signaling or decreased expression of the TGF- $\beta$ signaling molecules. Previous studies by others and ourselves have shown that TGF- $\beta$ is a potent inducer of apoptosis in several HCC cell lines ${ }^{5-7}$. Consistent with these in vitro findings, lower TGF- $\beta$ expression level is correlated with higher survivin expression and reduced apoptotic index in HCC tissues 8 . These observations suggest that TGF- $\beta$ may play a defensive role against tumor progression in HCC through regulation of apoptosis in tumor cells.

Parathyroid hormone-related protein (PTHrP) is a polyhormone protein that plays a role in a number of biological processes by acting via endocrine, paracrine, autocrine, and intracrine pathways ${ }^{9}$. There are three isoforms of human PTHrP peptide ranging in length from 139 to 173 amino acid residues ${ }^{10}$, all of which undergo are subjected to extensive post-translational processing including ubiquitin-proteasomal degradation ${ }^{11}$. PTHrP can exist as a secretory protein which functions as a classical circulating hormone to regulate calcium metabolism ${ }^{12}$ and mediate hypercalcemia of malignancy in cancer patients ${ }^{13}$. However, intracellular PTHrP also functions as an important regulator of cellular processes such as cell growth, differentiation 14 and apoptosis ${ }^{15}$. Evidence has accumulated that PTHrP mediates certain biological effects of TGF- $\beta$, including bone remodeling ${ }^{16}$ and apoptosis ${ }^{17}$. However, how PTHrP is regulated in HCC, especially by TGF- $\beta$, is still poorly understood. In the present study, we provided evidence to show that TGF- $\beta$ induced PTHrP protein degradation through the ubiquitin-proteasome system. Furthermore, we assessed the expression pattern of TGF- $\beta$ and PTHrP in HCC specimens and found that TGF- $\beta$ and PTHrP were differentially expressed in cancer cells and adjacent normal tissues. Our findings reveal a novel mechanism through which TGF- $\beta$ regulates the PTHrP protein during hepatocellular carcinogenesis.

\section{Experimental Procedures}

\section{Reagents and Expression Plasmids}

Human recombinant TGF- $\beta 1$ was purchased from R\&D Systems (Minneapolis, MN) and was dissolved in an aqueous solvent (vehicle) containing 4 $\mathrm{mM} \mathrm{HCl}$ and $1 \mathrm{mg} / \mathrm{ml}$ BSA. Non-essential amino acids and sodium pyruvate were purchased from Sigma (St Louis, MO). Dynabeads Protein G was purchased from Invitrogen (Grand Island, NY). Anti-PTHrP (rabbit polyclonal) and anti-TGF- $\beta$ (mouse monoclonal) antibodies were purchased from Boster (Wuhan, China). Antibodies against $\alpha$-tubulin, lamin A, Hsp90, and GAPDH were purchased from Santa Cruz Biotechnology (Santa Cruz, CA). Anti-HA and anti-EGFP antibodies were purchased from Covance (Princeton, NJ) and Abnova (Taipei, Taiwan), respectively. FuGENE 6 transfection reagent was purchased from Roche (Basel, Switzerland). Lactacystin was purchased from EMD Millipore (Darmstadt, Germany). The dominant negative mutant Smurf2 plasmid FLAG-Smurf2(C716A) 18 was a kind gift from Dr. Xinhua Feng at the Department of Molecular and Cellular Biology, Baylor College of Medicine (Houston, TX). Hemagglutinin-tagged ubiquitin (HA-Ub) 19 was obtained from Dr. Jonathan Leis at the Department of Microbiology and Immunology, Feinberg School of Medicine, Northwestern University (Evanston, IL). Enhanced green fluorescent protein (EGFP)-tagged construct expressing full-length PTHrP (EGFP-PTHrP) was kindly provided by Dr. Miriam Falzon at the Sealy Center for Molecular Science, University of Texas Medical Branch (Galveston, $\mathrm{TX).}$

\section{Cell Culture and Treatment}

Human HCC cell lines Hep3B, HepG2, and HuH-7 were maintained in modified Eagle medium (MEM) supplemented with 10\% FBS, 1X non-essential amino acids, $110 \mu \mathrm{g} / \mathrm{ml}$ of sodium pyruvate (for Hep3B and HepG2) and DMEM supplemented with 10\% FBS (for HuH-7), respectively. 293T human embryonic kidney (HEK-293T) cells were maintained in DMEM supplemented with 5 10\% FBS. All cells were maintained in a humidified incubator at $37^{\circ} \mathrm{C}$ with $5 \%$ $\mathrm{CO}_{2}$ and tested negative for mycoplasma contamination. The cells were starved in medium containing $0.1 \%$ FBS for $4 \mathrm{~h}$ and then treated with TGF- $\beta$ or vehi- 
cle for the indicated time durations followed by cell lysate preparation.

\section{Transfection}

For transfection, subconfluent Hep3B or 293T cells were transfected with EGFP-PTHrP or HA-Ub using FuGENE 6 as recommended by the manufacturer. 48 or $72 \mathrm{~h}$ after transfection, the cells were starved and treated with or without TGF- $\beta$ as described above.

\section{Preparation of Whole Cell Lysates and Nu- clear/Cytoplasmic Lysates}

Whole cell lysates were prepared from cultured cells using $1 \mathrm{X}$ cell lysis buffer (Cell Signaling Technology) with $1 \mathrm{X}$ protease inhibitor cocktail (Complete Mini, Roche) and 1 mM PMSF (Sigma) added. Nuclear and cytoplasmic lysates were prepared using the NE-PER nuclear and cytoplasmic extraction kit (Pierce) according to the manufacturer's protocol.

\section{Immunoprecipitation and Western Blot Analysis}

For immunoprecipitation, $100 \mu \mathrm{g}$ of cell lysates was immunoprecipitated for $1 \mathrm{~h}$ with $0.2 \mu \mathrm{g}$ of anti-EGFP or anti-HA antibody, followed by overnight incubation with $20 \mu$ lof washed Dynabeads Protein G at $4^{\circ} \mathrm{C}$. Bound proteins were washed three times with PBS containing $0.02 \%$ Tween 20 and eluted with $1.5 \mathrm{X}$ lithium dodecyl sulfate (LDS) sample buffer containing $50 \mathrm{mM}$ dithiothreitol (DTT). Immunoprecipitation complexes or cell lysates were separated on $4-12 \%$ gradient density precast NuPAGE denaturing gels followed by incubation with the respective primary antibody, the HRP-conjugated secondary antibody, and ECL development according to our standard protocol 20 .

\section{Patient Tissue Sections, Tissue Array, and Immunohistochemistry}

Formaldehyde-fixed paraffin-embedded HCC tissue sections $(4-\mu \mathrm{m}$-thick) were obtained from the First Affiliated Hospital of Hunan Normal University. Immunohistochemical staining for PTHrP and TGF- $\beta$ was carried out using the PV-9000 2-step plus Poly-HRP Anti-Mouse/Rabbit IgG Detection System. Briefly, the sections were deparaffinized in xylene and hydrated through a series of graded ethanols. The sections were incubated in 3\% hydrogen peroxide for 15 min to block endogenous peroxidase activity. Antigen retrieval was performed in citrate buffer $(\mathrm{pH}$ 6.0) with a microwave oven. After sections were cooled to room temperature, the slides were incubated with antibody against PTHrP or TGF- $\beta$ (both at 1:200 dilution) overnight at $4^{\circ} \mathrm{C}$. Subsequently, the
Polymer Helper and HRP-conjugated anti-mouse/rabbit IgG were applied, followed by coloration with $\mathrm{DAB} / \mathrm{H}_{2} \mathrm{O}_{2}$ and counterstaining with Mayer's hematoxylin.

Liver cancer tissue array slide (IMH-360) including 38 cases of HCC and combined HCC \& cholangiocarcinoma samples and 9 matched non-neoplastic liver tissues was purchased from Novus (Oakville, ON, Canada). The liver tissues were obtained from Chinese liver cancer patients. The tissue array slide was deparaffinized, hydrated, and subjected to antigen retrieval as with tissue sections. After quenching of endogenous peroxidase and alkaline phosphatase activity, the slide was subjected to double immunostaining using the monoclonal anti-TGF- $\beta$ antibody and the polyclonal anti-PTHrP antibody, respectively, at 1:200 dilution overnight at $4^{\circ} \mathrm{C}$. The expression of TGF- $\beta$ and PTHrP was revealed by the PV-9002 two-step plus Poly-HRP Anti-Mouse IgG Detection System and the Biotin SP-AP Detection System, respectively, following the manufacturer's instructions. After counterstaining with nuclear fast red, the sections were dehydrated, cleared in xylene and mounted.

Protein staining was evaluated under a light microscope by an authorized pathologist and confirmed by another experienced pathologist. Staining intensity was scored manually as $0=$ no staining, $1=$ weak staining, $2=$ moderate staining, and $3=$ strong staining. The percentage score of positively stained cells was designated as $1=0-5 \%, 2=5-10 \%, 3=$ $10-15 \%, 4=15-20 \%$, and $5>20 \%$. The final expression score was calculated by multiplying the intensity score with the percentage score of positive cells.

\section{Statistical Analysis}

The differences for TGF- $\beta$ and PTHrP expression between non-neoplastic and cancerous tissues were analyzed by the Student's $t$ test using the GraphPad Prism software (version 5.0, La Jolla, CA). A two-tailed value of $P<0.05$ was considered statistically significant.

\section{RESULTS}

\section{TGF- $\beta$ downregulates PTHrP protein level in HCC cells}

To investigate whether TGF- $\beta$ regulated PTHrP protein expression, we treated different HCC cell lines with TGF- $\beta$. As shown in Figure 1A, TGF- $\beta$ decreased PTHrP protein level in all three HCC lines, although for Hep3B cells, longer exposure of the blot was needed to reveal the reduction of PTHrP. Furthermore, a dose- and time-dependent decrease of both cytoplasmic and nuclear PTHrP was observed in 
HuH-7 cells (Figure 1B, 1C). This was confirmed by transient transfection with an EGFP-tagged plasmid containing full-length PTHrP in Hep3B cells and found that TGF- $\beta$ reduced the protein level of exogenous PTHrP in these transfected cells (Figure 1D). These data indicated that TGF- $\beta$ negatively regulated PTHrP protein level in HCC cell lines.

\section{TGF- $\beta$ promotes PTHrP degradation through the ubiquitin-proteasome pathway}

Since the ubiquitin-proteasome degradation pathway is the main pathway responsible for the degradation of secretory proteins ${ }^{21}$, we examined whether TGF- $\beta$ induced the degradation of PTHrP protein through the ubiquitin-proteasome pathway. As expected, pretreatment with lactacystin, a proteasomal inhibitor, reversed TGF- $\beta$-induced downregulation of PTHrP in Hep3B and $\mathrm{HuH}-7$ cells (Figure 2A, 2B). Ubiquitination of PTHrP by TGF- $\beta$ was confirmed by transient transfection of EGFP-tagged PTHrP (EGFP-PTHrP) and HA-tagged ubiquitin (HA-Ub) followed by immunoprecipitation-western blot analysis (Figure 2C). These data showed that TGF- $\beta$ induced PTHrP protein degradation through the ubiquitin-proteasome pathway.

To explore whether TGF- $\beta$ also downregulated the PTHrP protein at the translational level, we performed a metabolic labeling assay to evaluate the de novo protein synthesis of PTHrP in the presence of
TGF- $\beta$ stimulation. Contrary to our expectation, TGF- $\beta$ resulted in incorporation of L- $\left[{ }^{35} \mathrm{~S}\right]$ methionine into the PTHrP protein, suggesting increased (rather than decreased) synthesis of novel PTHrP protein molecules stimulated by TGF- $\beta$ (Supplemental Figure 1). These results confirmed that downregulation of PTHrP by TGF- $\beta$ occurred at the post-translational level, but not at the translational level.

\section{Smurf2 is responsible for TGF- $\beta$-induced ubiquitination of PTHrP}

The ubiquitination of the target protein is a multi-step process involving the sequential enzymatic reactions that catalyze the addition of the ubiquitin moiety to the protein of interest. The E3 ligase is a critical enzyme responsible for the ubiquitination of the target protein. It has previously been shown that Smad ubiquitination regulatory factor 2 (Smurf2) is the specific E3 ligase involved in TGF- $\beta$ signaling ${ }^{22}$. We examined whether Smurf2 was also involved in TGF- $\beta$-induced ubiquitination of PTHrP by transient transfection of a FLAG-tagged dominant-negative mutant of Smurf2 (Smurf2m) in HEK-293T cells. As shown in Figure 3, transfection with FLAG-Smurf2m completely abrogated TGF- $\beta$-induced ubiquitination of exogenously expressed PTHrP. These data suggest that Smurf2 is the E3 ligase responsible for TGF- $\beta$-induced ubiquitination of PTHrP.

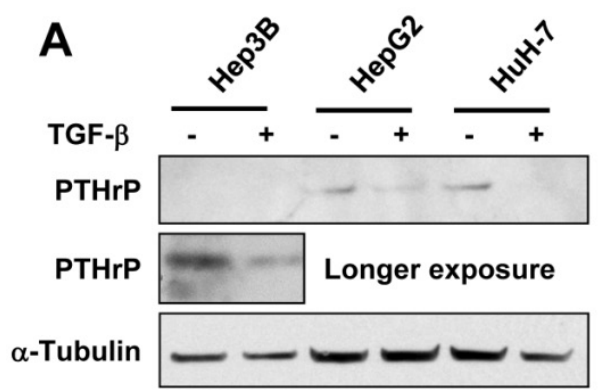

C

B
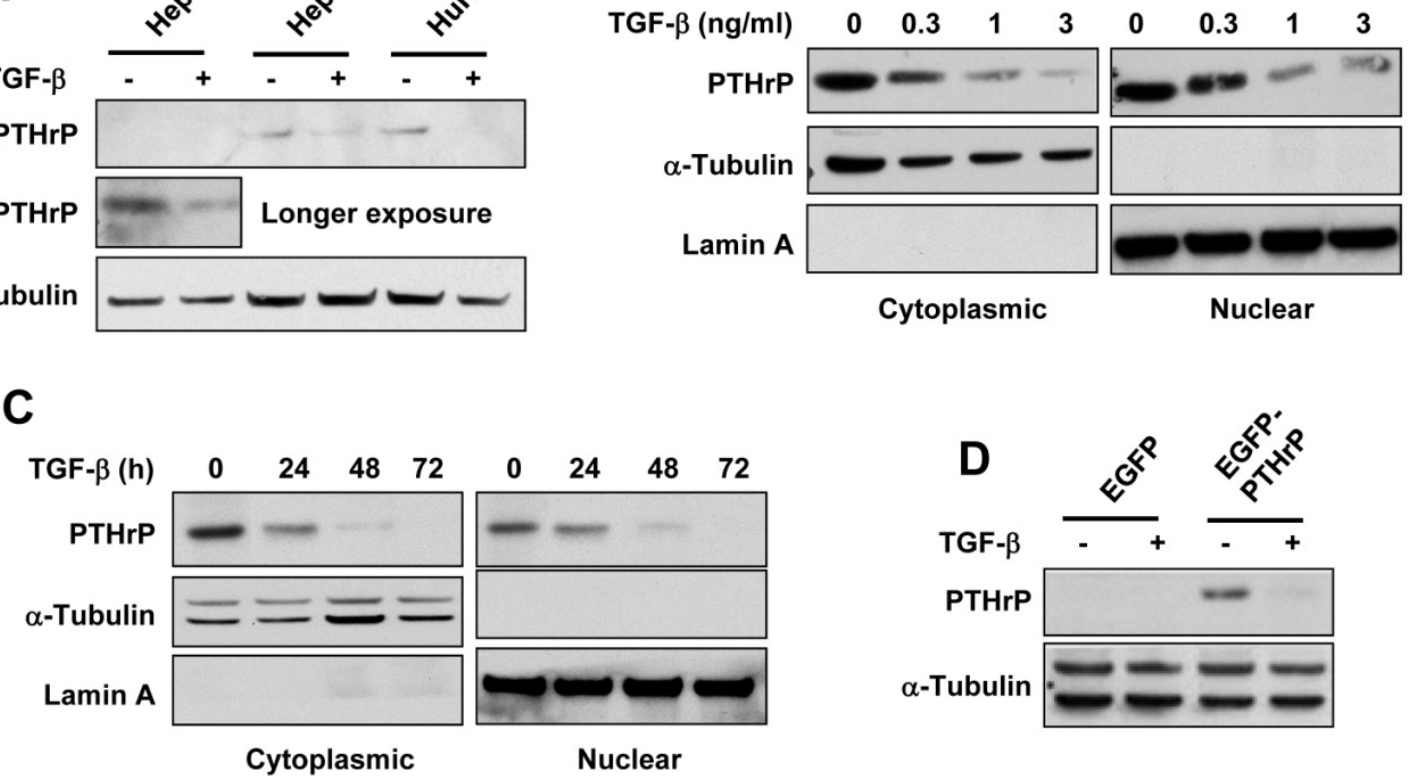

Figure 1. TGF- $\beta$ downregulates the protein level of PTHrP. (A) HCC cell lines were serum-starved for $4 \mathrm{~h}$ and treated with TGF- $\beta 1$ ( $1 \mathrm{ng} / \mathrm{ml}$ ) or vehicle for $48 \mathrm{~h}$. Whole cell lysates were prepared and subjected to western blot analysis using the anti-PTHrP antibody. The expression level of $\alpha$-tubulin was used as a loading control. (B, C) HuH-7 cells were serum-starved and treated with TGF- $\beta 1$ for $48 \mathrm{~h}$ at different concentrations (B) or at $1 \mathrm{ng} / \mathrm{ml}$ for different time durations (C). Cytoplasmic and nuclear lysates were prepared and subjected to western blot analysis for PTHrP. The expression level of $\alpha$-tubulin and lamin A was used as a loading control for cytoplasmic and nuclear lysates, respectively. (D) Hep3B cells were transfected with EGFP-tagged PTHrP expression plasmid (EGFP-PTHrP) or the control plasmid (EGFP). $72 \mathrm{~h}$ after transfection, the cells were serum-starved, treated with or without TGF- $\beta 1(1 \mathrm{ng} / \mathrm{ml})$, and subjected to western blot analysis for PTHrP. 


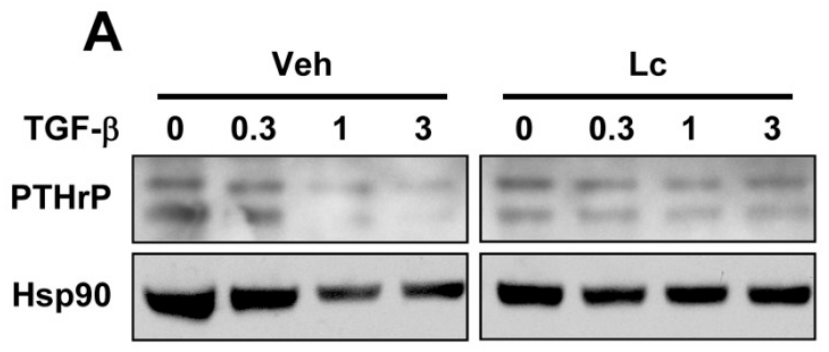

B
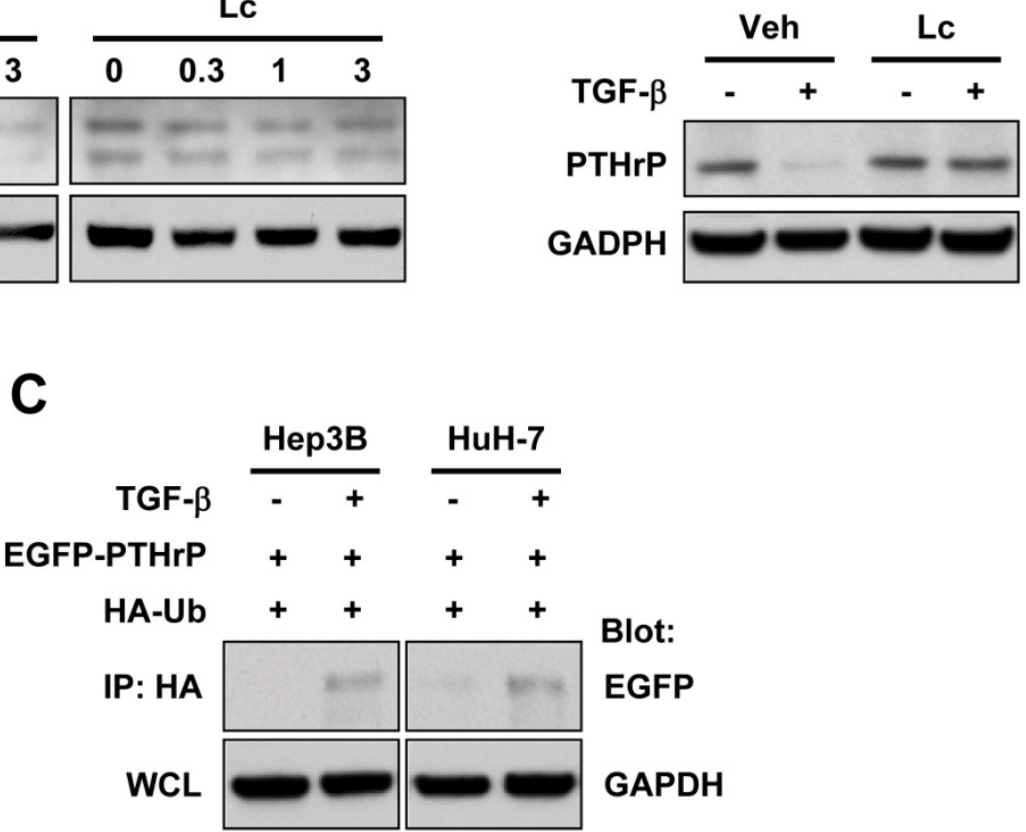

Figure 2. TGF- $\beta$ induces degradation of PTHrP through the ubiquitin-proteasome pathway. (A) Hep $3 B$ cells were serum-starved and treated for $48 \mathrm{~h}$ with different concentrations of TGF- $\beta 1$ in the presence or absence of lactacystin $(5 \mu \mathrm{M})$. Cell lysates were prepared and subjected to western blot analysis for PTHrP with Hsp90 expression as a loading control. (B) Serum-starved HuH-7 cells were treated with or without TGF- $\beta 1$ ( $1 \mathrm{ng} / \mathrm{ml})$ for $48 \mathrm{~h}$ and subjected to whole cell lysate preparation and western blot analysis. (C) Hep3B and HuH-7 cells were co-transfected with EGFP-tagged PTHrP (EGFP-PTHrP) and HA-tagged ubiquitin (HA-Ub). $72 \mathrm{~h}$ after transfection, the cells were serum-starved and treated with or without TGF- $\beta 1(1 \mathrm{ng} / \mathrm{ml})$ and subjected to whole lysate preparation and immunoprecipitation-western blot analysis.

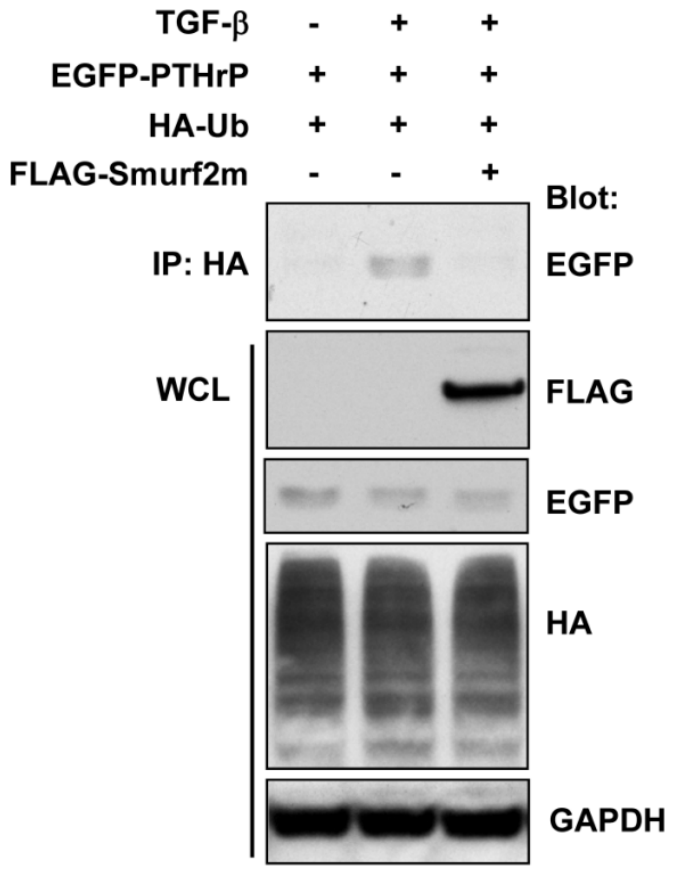

Figure 3. Smurf2 is responsible for TGF- $\beta$-induced ubiquitination of PTHrP. (A) HEK-293T cells were transfected with the plasmids as indicated, serum-starved and treated for $48 \mathrm{~h}$ with or without TGF- $\beta 1(1 \mathrm{ng} / \mathrm{ml})$. Whole cell lysates were prepared and subjected to immunoprecipitation and western blot analysis.

\section{TGF- $\beta$ and PTHrP are differentially expressed in cancer and adjacent normal tissues in HCC}

To elucidate the expression pattern of TGF- $\beta$ and PTHrP in HCC specimens, we carried out immunohistochemistry on human formaldehyde-fixed paraffin-embedded HCC tissue sections and an HCC tissue array. In a representative HCC patient specimen (Patient \#162475), PTHrP was abundantly expressed in the cancer cells of the HCC tissue, whereas high-level expression of TGF- $\beta$ was limited to the adjacent non-neoplastic tissue (Figure 4). A further tissue array analysis of 38 human HCC specimens and 9 adjacent non-neoplastic tissues was carried out by performing double immunostaining for both PTHrP and TGF- $\beta$ simultaneously. In the tissue array, the protein staining level was expressed as the product of the number of stained cells and the staining intensity. Consistent with the results obtained with HCC specimens, PTHrP was predominantly expressed in the cancer tissues, whereas TGF- $\beta$ expression was observed mainly in the non-neoplastic adjacent tissues. Representative images for PTHrP and TGF- $\beta$ expression were presented in Figure 5A and 5B. Statistical analyses were shown in Figure 5C (PTHrP expression in non-neoplastic tissues vs. cancer tissues, $P<0.05)$ and 5D (TGF- $\beta$ expression in non-neoplastic tissues vs. cancer tissues, $P<0.01$ ). 

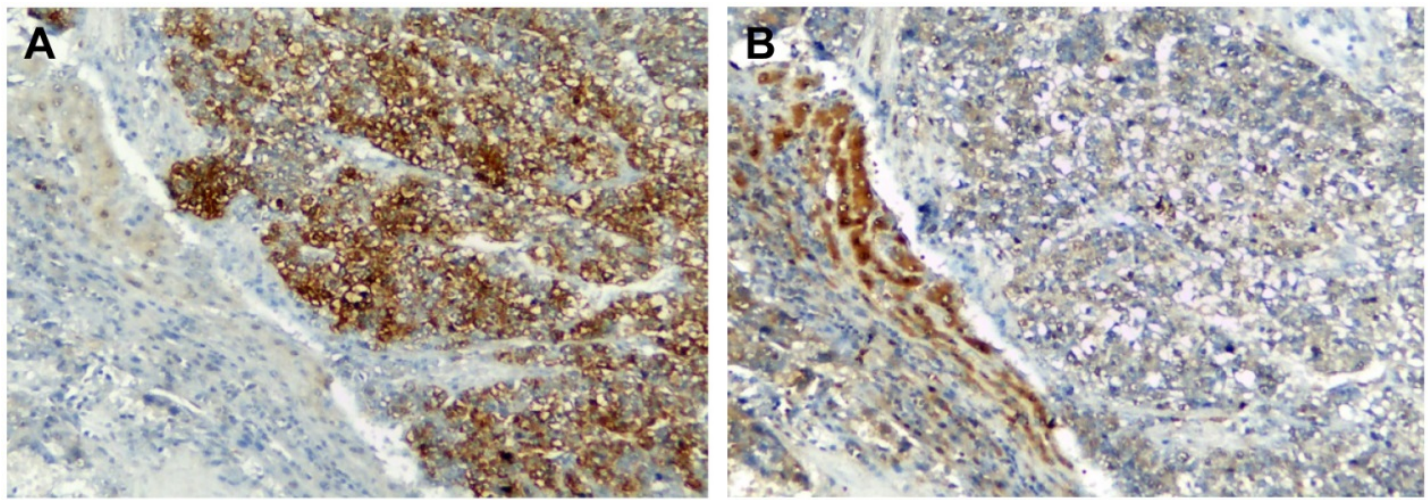

Figure 4. Immunolocalization of TGF- $\beta$ and PTHrP in HCC. Human HCC specimens were stained for PTHrP (A) and TGF- $\beta$ (B) by immunohistochemistry using the $\mathrm{HRP}$ and DAB/ $\mathrm{H}_{2} \mathrm{O}_{2}$ development system. The nuclei were counterstained with hematoxylin. Shown is a representative pattern of staining of PTHrP and TGF- $\beta$ in a $\mathrm{HCC}$ patient tissue (ID \#162475). Original magnification: x100.
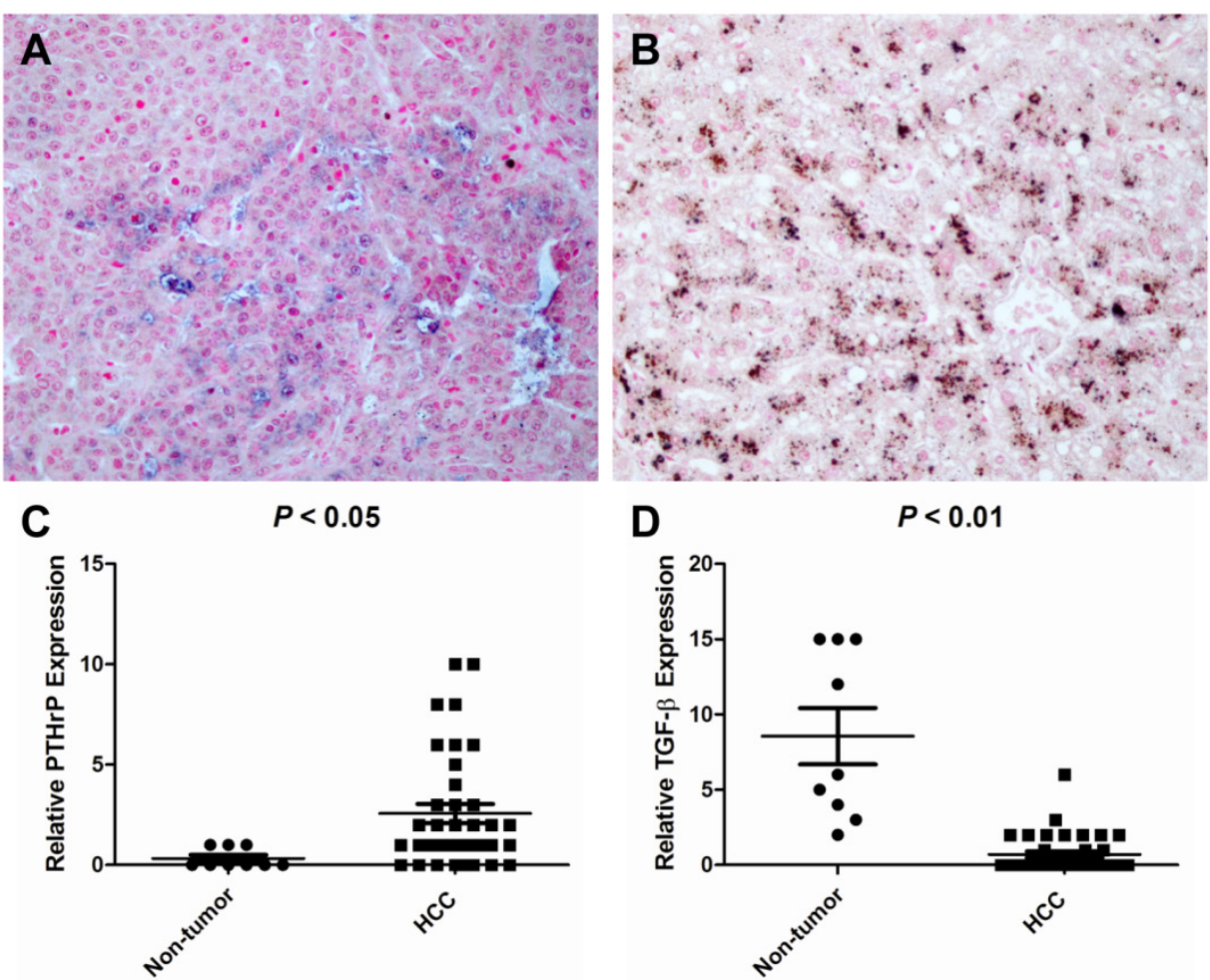

Figure 5. Tissue array analysis of TGF- $\beta$ and PTHrP expression in HCC and non-cancerous specimens. A human tissue array containing 38 HCC cancer tissues and 9 non-neoplastic liver tissues was double-stained for PTHrP and TGF- $\beta$ by immunohistochemistry using the Poly-HRP Anti-Mouse lgG Detection System (brown staining TGF- $\beta$ ) and the Biotin SP-AP Detection System (blue staining - PTHrP), respectively. The nuclei were counterstained with nuclear fast red. (A) A representative image showing PTHrP staining but no TGF- $\beta$ staining in the HCC cancer cells in a HCC patient (ID \#08). (B) TGF- $\beta$ was intensely stained in the matched non-neoplastic liver tissue of the same patient. (C) PTHrP expression level was considerably higher in HCC tissues than in the non-neoplastic liver tissues. (D) TGF- $\beta$ expression was high in the non-neoplastic liver tissues but low in HCC cancer tissues. Original magnification: $x 400$.

\section{Discussion}

TGF- $\beta$ signaling plays a critical role in the development of liver cancer through regulation of cell processes such as epithelial-to-mesenchymal transition and apoptosis. Several studies have focused on regulating TGF- $\beta$ signaling, especially at the level of substrates and receptors ${ }^{23-25}$. However, little is known about the interaction between TGF- $\beta$ and other signaling pathways. PTHrP is a secretory polyhormone that plays fundamental roles in various functional aspects of cell biology. In the present study, we have provided evidence to show that TGF- $\beta$ induced protein degradation of PTHrP through the ubiquitin-proteasome-mediated pathway in a Smurf2-depenent manner. These observations led us to propose that TGF- $\beta$ may antagonize the actions of PTHrP during the process of liver carcinogenesis, which was supported using HCC tissue specimens and microarray. Our findings represent the first demonstration that TGF- $\beta$ antagonizes PTHrP through a post-translational mechanism in HCC.

PTHrP was first discovered as an etiological factor of humoral hypercalcemia of malignancy 
(HHM) in certain types of cancers such as breast, lung, renal, ovarian and pancreatic carcinomas and myeloma, which show a strong tendency to metastasize to bone ${ }^{26}$. Subsequently, PTHrP was found to be expressed in numerous types of cancers with clinical manifestations of HHM. In HCC, serum PTHrP concentration was increased (7.1 to $33.2 \mathrm{pmol} / \mathrm{l}$ ) compared with normal controls 27 . Our study demonstrated that PTHrP was expressed at a much higher level in HCC cancer tissues than the non-cancerous tissues (Figures 4 and 5). Tumor-derived PTHrP can act in different ways to modulate tumor growth, progression, and metastasis. For example, PTHrP acts in an autocrine and a intracrine manner to promote apoptosis resistance and survival of the tumor cells 28 .

As mentioned earlier, the regulation of PTHrP in carcinogenesis is far from clear. The situation is made more complicated by the involvement of TGF- $\beta$, which is a well-known regulator of PTHrP in bone metastasis, such as occurs in breast cancer ${ }^{29,30}$. Previous study by us and others revealed that TGF- $\beta$ stimulated PTHrP mRNA expression ${ }^{17,31}$, stability ${ }^{32}$ and secretion 17,31 in different cell types. In terms of PTHrP regulation, TGF- $\beta$ may play both agonizing and antagonizing effects in different cancer lines, depending on the stage of cancer progression and the type of cancer involved. Alternatively, increased protein secretion and degradation of PTHrP stimulated by TGF- $\beta$ may drive the mRNA synthesis (and possibly de novo protein synthesis as seen in the current study [Supplemental Figure 1]) of PTHrP as the cell's attempt to compensate for the decreased intracellular protein level of PTHrP. A generalized model is needed to explain the regulation of PTHrP by TGF- $\beta$ at the transcriptional, translational and post-translational levels, which is beyond the scope of the current study.

In HCC, TGF- $\beta$ has a pivotal role in orchestrating and regulating the corresponding phenotypes of HCC. It is possible that PTHrP in HCC cells is anti-apoptotic, favoring HCC cell survival, proliferation, and possibly metastasis. It can be speculated that TGF- $\beta$ exerts its cytostatic effect in liver cells through the regulation of PTHrP via ubiquitin-proteasome-mediated degradation of intracellular PTHrP protein. TGF- $\beta$-induced ubiquitin-proteasomal degradation of PTHrP in HCC is in concordance with previous reports that PTHrP undergoes ubiquitin-mediated proteasomal degradation in other cell types 33,34 . The net effect of the actions of TGF- $\beta$ is the reduction of intracellular PTHrP and eventual induction of cytostasis of hepatocytes.

The mechanism of the cross-talk between TGF- $\beta$ and PTHrP signaling is critically relevant for devising therapeutic modalities in order to stimulate TGF- $\beta$ expression and suppression of liver tumor growth. Based on the observations of us and others, we propose that TGF- $\beta$, which is functional in normal liver tissues or at the initial stage of liver carcinogenesis, exerts its anti-cancer effect through ubiquitin-proteasome-mediated degradation of PTHrP. This beneficial function of TGF- $\beta$ was lost in HCC suppressed TGF- $\beta$ expression and subsequent increased PTHrP. In this sense, up-regulation of TGF- $\beta$ ligand production is one option to restrain further HCC development in cells that have intact TGF- $\beta$ signaling. This may explain, at least partly, why contrary to the beneficial outcome of anti-TGF- $\beta$ treatment in animal disease models ${ }^{35}$, only limited positive or even adverse results are documented for human liver diseases including HCC. Therefore, caution should be taken when targeting TGF- $\beta$ signaling for the treatment of human HCC.

We have revealed a novel mechanism of regulation of PTHrP by the multifunctional cytokine, TGF- $\beta$, i.e., promotion of degradation of PTHrP through the ubiquitin-proteasome system. The TGF- $\beta$-PTHrP signaling axis provides a novel target of therapeutic intervention that has the potential to be used to sensitize HCC cells to pro-apoptotic signals.

\section{Supplementary Material}

Supplemental Methods, Supplemental Figure 1.

http://www.jcancer.org/v06p0511s1.pdf

\section{Acknowledgements}

We thank Dr. Yu Liu at the Department of Pathology, the First Affiliated Hospital of Hunan Normal University for providing the liver cancer tissue sections. We also thank Dr. Xinhua Feng at the Department of Molecular and Cellular Biology, Baylor College of Medicine for providing FLAG-Smurf2 (C716A), Dr. Jonathan Leis at the Department of Microbiology and Immunology, Feinberg School of Medicine, Northwestern University for providing HA-Ub, and Dr. Miriam Falzon at the Sealy Center for Molecular Science, University of Texas Medical Branch for providing the PTHrP plasmid. This project was supported in part by Hunan Normal University Startup Fund for Returned Overseas Scholars (130608).

\section{Competing Interests}

The authors have declared that no competing interest exists.

\section{References}

1. Jemal A, Bray F, Center MM, Ferlay J, Ward E, Forman D: Global cancer statistics. CA Cancer J Clin 2011, 61:69-90.

2. Majumdar A, Curley SA, Wu X, Brown P, Hwang JP, Shetty K, Yao ZX, He AR, Li S, Katz L, Farci P, Mishra L: Hepatic stem cells and transforming growth 
factor beta in hepatocellular carcinoma. Nat Rev Gastroenterol Hepatol 2012, 9:530-538.

3. Okazaki I, Inagaki Y: Novel strategies for hepatocellular carcinoma based on MMPs science. Anticancer Agents Med Chem 2012, 12:753-763.

4. Derynck R, Zhang YE: Smad-dependent and Smad-independent pathways in TGF-beta family signalling. Nature 2003, 425:577-584.

5. Lin JK, Chou CK: In vitro apoptosis in the human hepatoma cell line induced by transforming growth factor beta 1. Cancer Res 1992, 52:385-388.

6. Kim KY, Kim BC, Xu Z, Kim SJ: Mixed lineage kinase 3 (MLK3)-activated p38 MAP kinase mediates transforming growth factor-beta-induced apoptosis in hepatoma cells. J Biol Chem 2004, 279:29478-29484.

7. Caja L, Sancho P, Bertran E, Fabregat I: Dissecting the effect of targeting the epidermal growth factor receptor on TGF-beta-induced-apoptosis in human hepatocellular carcinoma cells. J Hepatol 2011, 55:351-358.

8. Ikeguchi M, Iwamoto A, Taniguchi K, Katano K, Hirooka Y: The gene expression level of transforming growth factor-beta (TGF-beta) as a biological prognostic marker of hepatocellular carcinoma. J Exp Clin Cancer Res 2005, 24:415-421.

9. Strewler GJ: The parathyroid hormone-related protein. Endocrinol Metab Clin North Am 2000, 29:629-645.

10. Burtis WJ: Parathyroid hormone-related protein: structure, function, and measurement. Clin Chem 1992, 38:2171-2183.

11. Fiaschi-Taesch NM, Stewart AF: Minireview: parathyroid hormone-related protein as an intracrine factor--trafficking mechanisms and functional consequences. Endocrinology 2003, 144:407-411.

12. Ye Y, Wang C, Du P, Falzon M, Seitz PK, Cooper CW: Overexpression of parathyroid hormone-related protein enhances apoptosis in the rat intestinal cell line, IEC-6. Endocrinology 2001, 142:1906-1914.

13. Burtis WJ, Wu T, Bunch C, Wysolmerski JJ, Insogna KL, Weir EC, Broadus AE, Stewart AF: Identification of a novel 17,000-dalton parathyroid hormone-like adenylate cyclase-stimulating protein from a tumor associated with humoral hypercalcemia of malignancy. J Biol Chem 1987, 262:7151-7156.

14. Sourbier C, Massfelder T: Parathyroid hormone-related protein in human renal cell carcinoma. Cancer Lett 2006, 240:170-182

15. Kremer R, Li J, Camirand A, Karaplis AC: Parathyroid hormone related protein (PTHrP) in tumor progression. Adv Exp Med Biol 2011, 720:145-160.

16. Serra R, Karaplis A, Sohn P: Parathyroid hormone-related peptide (PTHrP)-dependent and -independent effects of transforming growth factor beta (TGF-beta) on endochondral bone formation. J Cell Biol 1999, 145:783-794.

17. Cao Y, Zhang W, Gao X, Zhang G, Falzon M, Townsend CM, Jr., Hellmich MR, Ko TC: PTHrP is a novel mediator for TGF-beta-induced apoptosis. Regul Pept 2013, 184:40-46.

18. Wrighton $\mathrm{KH}$, Lin $\mathrm{X}$, Feng $\mathrm{XH}$ : Critical regulation of TGFbeta signaling by Hsp90. Proc Natl Acad Sci U S A 2008, 105:9244-9249.

19. Vana ML, Tang Y, Chen A, Medina G, Carter C, Leis J: Role of Nedd4 and ubiquitination of Rous sarcoma virus Gag in budding of virus-like particles from cells. J Virol 2004, 78:13943-13953.

20. Deng X, He G, Levine A, Cao Y, Mullins C: Adenovirus-mediated expression of TIMP-1 and TIMP-2 in bone inhibits osteolytic degradation by human prostate cancer. Int J Cancer 2008, 122:209-218.

21. Hoseki J, Ushioda R, Nagata K: Mechanism and components of endoplasmic reticulum-associated degradation. J Biochem 2010, 147:19-25.

22. Lin $X$, Liang $M$, Feng $\mathrm{XH}$ : Smurf2 is a ubiquitin E3 ligase mediating proteasome-dependent degradation of Smad2 in transforming growth factor-beta signaling. J Biol Chem 2000, 275:36818-36822.

23. Kim EY, Kim BC: Lipopolysaccharide inhibits transforming growth factor-beta1-stimulated Smad6 expression by inducing phosphorylation of the linker region of Smad3 through a TLR4-IRAK1-ERK1/2 pathway. FEBS Lett 2011, 585:779-785.

24. Meyer C, Godoy P, Bachmann A, Liu Y, Barzan D, Ilkavets I, Maier P, Herskind C, Hengstler JG, Dooley S: Distinct role of endocytosis for Smad and non-Smad TGF-beta signaling regulation in hepatocytes. J Hepatol 2011, 55:369-378.

25. Malapeira J, Esselens C, Bech-Serra JJ, Canals F, Arribas J: ADAM17 (TACE) regulates TGFbeta signaling through the cleavage of vasorin. Oncogene 2011, 30:1912-1922.

26. McCauley LK, Martin TJ: Twenty-five years of PTHrP progress: from cancer hormone to multifunctional cytokine. J Bone Miner Res 2012, 27:1231-1239

27. Yen TC, Hwang SJ, Wang CC, Lee SD, Yeh SH: Hypercalcemia and parathyroid hormone-related protein in hepatocellular carcinoma. Liver 1993, 13:311-315.

28. Soki FN, Park SI, McCauley LK: The multifaceted actions of PTHrP in skeletal metastasis. Future Oncol 2012, 8:803-817.

29. Lindemann RK, Ballschmieter P, Nordheim A, Dittmer J: Transforming growth factor beta regulates parathyroid hormone-related protein expression in MDA-MB-231 breast cancer cells through a novel Smad/Ets synergism. J Biol Chem 2001, 276:46661-46670.

30. Kakonen SM, Selander KS, Chirgwin JM, Yin JJ, Burns S, Rankin WA, Grubbs BG, Dallas M, Cui Y, Guise TA: Transforming growth factor-beta stimulates parathyroid hormone-related protein and osteolytic metastases via Smad and mitogen-activated protein kinase signaling pathways. J Biol Chem 2002, 277:24571-24578

31. Sellers RS, LeRoy BE, Blomme EA, Tannehill-Gregg S, Corn S, Rosol TJ: Effects of transforming growth factor-beta1 on parathyroid hormone-related protein
mRNA expression and protein secretion in canine prostate epithelial, stromal, and carcinoma cells. Prostate 2004, 58:366-373.

32. Sellers RS, Capen CC, Rosol TJ: Messenger RNA stability of parathyroid hormone-related protein regulated by transforming growth factor-beta1. Mol Cell Endocrinol 2002, 188:37-46.

33. Meerovitch K, Wing S, Goltzman D: Preproparathyroid hormone-related protein, a secreted peptide, is a substrate for the ubiquitin proteolytic system. J Biol Chem 1997, 272:6706-6713.

34. Meerovitch K, Wing S, Goltzman D: Proparathyroid hormone-related protein is associated with the chaperone protein $\mathrm{BiP}$ and undergoes proteasome-mediated degradation. J Biol Chem 1998, 273:21025-21030.

35. Breitkopf K, Godoy P, Ciuclan L, Singer MV, Dooley S: TGF-beta/Smad signaling in the injured liver. Z Gastroenterol 2006, 44:57-66. 